\title{
Ethical perception: are differences between ethnic groups situation dependent?
}

\begin{abstract}
This study was conducted to determine how culture influences the ethical perception of managers. Most studies conducted so far have only stated similarities and differences in ethical perception between cultural or ethnic groups and little attention has been paid towards understanding how cultural values influence the ethnic groups' ethical perception. Moreover, most empirical research in this area has focused on moral judgement, moral decision making and action, with limited empirical work in the area of ethical perception. A total of 22 interviews were conducted and the questionnaire survey yielded 272 managerial responses. Three implications were obtained based on the findings of the study. The first implication is that differences in ethical perception can exist when one culture attributes moral significance to something that another culture does not. The results of the study also suggest that similarities in ethical perception can occur when a situation is viewed as an accepted and institutionalised part of doing business. Finally, the findings of the study also show that the influence of culture on ethical perception varied according to the different types of scenarios.
\end{abstract}

